\title{
The Methyl Red Test in Peptone Media
}

\author{
By MARY G. JENNENS \\ National Collection of Type Cultures, Colindale Avenue, London, N.W. 9
}

\begin{abstract}
SUMMARY: The methyl red (MR) reactions of eighteen strains of coliform bacteria were investigated. Two different media were used, glucose phosphate peptone broth and a liquid defined medium. In the glucose phosphate peptone medium the MR test was found to vary with the brand of peptone used, but the defined inorganic salt + glucose medium gave constant results throughout. After 5 days of incubation at $30^{\circ}$ in a glucose phosphate peptone medium twelve substrains selected from each of three strains showed a maximum $\mathrm{pH}$ difference of $0 \cdot 2$ unit. When the test strains were inoculated into two batches of this medium made up on different days, $\mathrm{pH}$ differences up to $0 \cdot 6$ unit were obtained between the two batches.
\end{abstract}

The methyl red (MR) test devised by Clark \& Lubs (1915) has been used mainly to distinguish between coliform bacteria. The organisms are grown in a medium containing glucose, phosphate and peptone, and after incubation at $30^{\circ}$ for 5 days cultures are tested by the addition of a few drops of methyl red solution. Escherichia coli cultures show a red colour (MR-positive) and Klebsiella aerogenes (syn. Bacterium aerogenes, Aerobacter aerogenes) a yellow colour (MR-negative). Later, Clark \& Lubs (1917) described an improved medium for the test in which all the ingredients were chemically defined. Levine (1916) showed that there was a high negative correlation between the MR and Voges-Proskauer (VP) tests, but Chen \& Rettger (1920) described some apparently pure cultures which were persistently $\mathbf{M R}+, \mathrm{VP}+$. Taylor, Clegg, Dowson, Hiscox \& Richards (1949) maintained that when MR +, vP+ reactions are obtained an impure culture should be suspected since the $\mathrm{MR}_{\mathrm{R}}$ and VP reactions are 'invariably inversely correlated' when the tests are correctly carried out on pure cultures. Fouad \& Richards (1952) described a new medium not containing peptone in which $\mathrm{MR}-$, VP + reactions were given by pure cultures which had been $\mathrm{MR}+$, $\mathrm{vP}+$ in glucose peptone medium.

In our collection we have a series of coliform bacteria which have given different $\mathrm{MR}$ reactions in the hands of workers in different laboratories. It was decided to see whether more consistent results could be obtained when these organisms were tested in Fouad \& Richards's (FR) defined medium than when tested in glucose peptone medium.

\section{MATERIALS AND METHODS}

Dr T. Richards kindly supplied eleven strains that he had found to give $\mathrm{MR}+, \mathrm{VP}+$ reactions in glucose phosphate medium, ten of which gave $\mathrm{MR}-$, $\mathbf{v P}+$ reactions in his defined medium. Seven coliform organisms already in the National Collection of Type Cultures, which had given inconsistent MR reactions, were also used. All these eighteen cultures consistently gave positive reactions in the $\mathrm{VP}$ test. 
Media. The glucose phosphate peptone medium was made up with the following formula $(\%, w / v)$ : glucose, 0.5 ; peptone, $0.5 ; \mathrm{K}_{2} \mathrm{HPO}_{4}, 0.5$, in distilled water. Three different brands of peptone were used, and the $\mathbf{K}_{2} \mathbf{H P O}_{4}$ was stored in a desiccator over $\mathrm{CaCl}_{2}$.

RF glucose salt medium had the formula $(\%, w / v)$ : glucose, $0.5 ; \mathrm{NaCl}$, $0.5 ; \mathrm{K}_{2} \mathrm{HPO}_{4}, 0.5 ; \mathrm{KH}_{2} \mathrm{PO}_{4}, 0.2 ;\left(\mathrm{NH}_{4}\right) \mathrm{H}_{2} \mathrm{PO}_{4}, 0.2 ; \mathrm{MgSO}_{4} .7 \mathrm{H}_{2} \mathrm{O}, 0.02$; $\mathrm{MnSO}_{4} .4 \mathrm{H}_{2} \mathrm{O}, 0 \cdot 002 ; \mathrm{FeCl}_{3}, 0 \cdot 00005$ (Fouad \& Richards, 1952).

Methyl red (MR) test. Strains were grown overnight at $30^{\circ}$ in peptone water and were subcultured to glucose phosphate peptone medium and to $\mathbf{R F}$ glucose salt medium. Cultures were incubated at $30^{\circ}$ and a few drops of a solution of $0.04 \%(\mathrm{w} / \mathrm{v})$ methyl red in ethanol were added at intervals as described in the individual experiments.

Voges-Proskauer $(V P)$ test. Cultures were grown at $30^{\circ}$ for 5 days in glucose phosphate peptone medium and tested each day by Batty-Smith's (1941) modification of Barritt's (1936) $\alpha$-naphthol method.

\section{RESULTS}

Three batches of glucose phosphate peptone medium, each containing a different brand of peptone, were made up at the same time, and three batches of RF medium were made up by three different assistants.

\section{Table 1. The effect of different media and duration of incubation on the MR test}

Media 4, 5 and $6=$ glucose phosphate peptone media; $9=$ FR glucose salt medium.

\begin{tabular}{|c|c|c|c|c|c|c|}
\hline & & & & ays & pati & \\
\hline & & & 1 & 2 & $\mathbf{3}$ & $\mathbf{5}$ \\
\hline Strain & Medium & Pentone & & Rest & tes & \\
\hline 8687 & 4 & A & + & - & - & - \\
\hline & 5 & B & + & \pm & - & - \\
\hline & 6 & C & - & $\bar{z}$ & - & - \\
\hline & 9 & None & - & - & - & - \\
\hline 8835 & 4 & $\mathbf{A}$ & + & \pm & - & - \\
\hline & 5 & B & + & + & + & + \\
\hline & 6 & $\mathbf{C}$ & + & - & - & - \\
\hline & 9 & None & \pm & - & - & - \\
\hline 8845 & 4 & A & + & + & + & + \\
\hline & 5 & B & + & + & + & t \\
\hline & 6 & C & + & + & - & - \\
\hline & 9 & None & \pm & - & - & - \\
\hline 418 & 4 & A & - & - & - & - \\
\hline (control) & 5 & B & - & - & - & - \\
\hline & 6 & C & - & - & - & - \\
\hline & 9 & None & - & - & - & - \\
\hline 8179 & 4 & $\mathbf{A}$ & + & + & + & + \\
\hline (control) & 5 & B & + & + & + & + \\
\hline & 6 & C & + & + & + & + \\
\hline & 9 & None & + & + & + & + \\
\hline
\end{tabular}


The eighteen test cultures, together with the controls, E. coli (NCTC 8179) and $K$. aerogenes (NCTC 418), were inoculated into several tubes of each medium. All cultures were incubated at $30^{\circ}$ and on the 1st, 2nd, 3rd and 5th days a tube of each was withdrawn for an MR test. Each batch of glucose phosphate medium gave different results when used for the methyl red test. On the first day, most cultures were Mr-positive. Subsequently, some cultures became MR-negative while others remained MR-positive up to the 5th day. Table 1 shows the results of MR tests on three representative strains and the two controls. The three batches of FR medium (only one batch shown in Table 1) behaved more consistently.

The MR reactions after 5 days incubation of all the strains grown in three media containing different peptones are shown in Table 2. All cultures, except the control $E$. coli and NCTC 8696, were MR-negative in FR medium. In this experiment NCTC 8696 gave a negative MR reaction with one batch of peptone medium, but this result was not reproducible.

Table 2. MR reaction at 5 days in $\mathbf{F R}$ medium and in glucose phosphate peptone media containing different brands of peptone

\begin{tabular}{|c|c|}
\hline & Media \\
\hline \multirow[t]{3}{*}{ FR defined } & Glucose peptone media \\
\hline & Peptones \\
\hline & B \\
\hline
\end{tabular}

\begin{tabular}{lllll} 
Strain & \multicolumn{4}{c}{ MR reaction } \\
\cline { 2 - 5 } $\mathbf{8 6 9 6}$ & + & - & + & + \\
$\mathbf{8 8 3 5}$ & - & - & + & - \\
$\mathbf{8 8 4 4}$ & - & - & + & - \\
$\mathbf{8 8 4 5}$ & - & + & + & - \\
$\mathbf{8 8 4 7}$ & - & - & + & - \\
$\mathbf{8 8 5 1}$ & - & - & \pm & - \\
$\mathbf{1 2}$ others & - & - & - & - \\
$\mathbf{4 1 8}$ (control) & - & - & - & - \\
$\mathbf{8 1 7 9}$ (control) & + & + & + & +
\end{tabular}

When the strains were tested repeatedly after 5 days incubation in glucose phosphate medium containing peptone $\mathrm{B}$, eight gave consistent results (three MR-positive and five MR-negative) but ten were variable, sometimes being MR-positive and sometimes MR-negative. In tests using FR medium seventeen of the eighteen strains were consistently MR-negative.

\section{Experiments to check the purity of the cultures}

To exclude contamination as a cause of inconsistency, three strains that had given the most variable results were replated, and twelve colonies selected from each. The thirty-six substrains so obtained were inoculated into tubes of the same batch of glucose phosphate peptone medium containing bromcresol purple, so that $\mathrm{pH}$ values between $5 \cdot 2$ and $6 \cdot 8$ could be estimated by inspection. Unlike methyl red, bromcresol purple was not decolorized by the 
coliform bacteria. The results of this experiment ('Table 3) showed that the twelve substrains of each culture behaved in a similar manner: after 5 days incubation the maximum $\mathrm{pH}$ difference between substrains of any culture was $\mathbf{0 . 2}$ unit. Thus, strains which in previous experiments showed variable MR reactions in three different batches of peptone medium, produced substrains which reacted consistently when tested in one batch. This indicated that the variable results of earlier experiments were not due to the use of impure cultures; rather were they due to differences in the media used.

Table 3. $\mathrm{pH}$ values attained after 5 days incubation in glucose phosphate peptone medium by substrains of three coliform cultures

The $\mathrm{pH}$ values were estimated by means of bromeresol purple.

\begin{tabular}{cccc} 
& \multicolumn{3}{c}{ Strain } \\
\cline { 2 - 3 } Substrain & $\overbrace{8686}^{8692}$ & $\mathbf{8 8 4 5}$ \\
1 & \multicolumn{3}{c}{ pH value } \\
2 & $6 \cdot 0$ & $6 \cdot 0$ & $5 \cdot 4$ \\
3 & $6 \cdot 0$ & $6 \cdot 2$ & $5 \cdot 4$ \\
4 & $6 \cdot 0$ & $6 \cdot 0$ & $5 \cdot 4$ \\
5 & $6 \cdot 0$ & $6 \cdot 2$ & $5 \cdot 4$ \\
6 & $6 \cdot 0$ & $6 \cdot 2$ & $5 \cdot 4$ \\
7 & $6 \cdot 0$ & $6 \cdot 2$ & $5 \cdot 4$ \\
8 & $6 \cdot 0$ & $6 \cdot 0$ & $5 \cdot 4$ \\
9 & $6 \cdot 0$ & $6 \cdot 2$ & $5 \cdot 4$ \\
10 & $6 \cdot 0$ & $6 \cdot 2$ & $5 \cdot 4$ \\
11 & $6 \cdot 0$ & $6 \cdot 0$ & $5 \cdot 4$ \\
12 & $5 \cdot 8$ & $6 \cdot 0$ & $5 \cdot 4$ \\
& $6 \cdot 0$ & $6 \cdot 2$ & $5 \cdot 4$
\end{tabular}

Two batches of glucose phosphate peptone medium containing bromcresol purple were made up on different days; both contained peptone from the same sample. The eighteen strains were grown for 5 days in each batch of medium and the $\mathrm{pH}$ values attained are shown in Table 4 . Where differences in $\mathrm{pH}$ existed, batch 1 tended to show the lower value; a difference of $0 \cdot 6$ unit was shown by three strains.

It is well known that glucose phosphate peptone medium is difficult to sterilize and that when overheated is unsatisfactory in use. Therefore, before sterilization a batch was divided into two portions. Heat was applied normally to one portion and $10 \mathrm{lb} . / \mathrm{sq}$. in. pressure was attained in $15 \mathrm{~min}$. ; to the second portion the heat was applied more slowly and $40 \mathrm{~min}$. were required to attain the same pressure. When the eighteen coliform cultures were tested in these two portions of medium, only one strain (NCTC 8845) showed a difference of $0 \cdot 6$ unit.

\section{DISCUSSION}

It has been shown by many workers that an inverse correlation generally exists between the MR and VP reactions, and as all the strains used in these experiments were VP-positive it was to be expected that they would be MRnegative. However, in glucose phosphate peptone media some of them were 
Table 4. $\mathrm{pH}$ values attained on the fifth day by eighteen strains in two different batches of glucose phosphate peptone medium

The $\mathrm{pH}$ values were estimated by means of bromcresol purple

\begin{tabular}{|c|c|c|c|}
\hline \multirow[b]{2}{*}{ Strain no. } & \multicolumn{2}{|c|}{$\mathrm{pH}$ of medium } & \multirow{2}{*}{$\begin{array}{l}\text { Difference } \\
\text { in pH } \\
\text { (unit) }\end{array}$} \\
\hline & Batch 1 & Batch 2 & \\
\hline 8686 & $5 \cdot 8$ & $6 \cdot 0$ & $0 \cdot 2$ \\
\hline 8687 & $5 \cdot 8$ & $5 \cdot 8$ & 0 \\
\hline 8688 & $5 \cdot 4$ & $5 \cdot 6$ & $0 \cdot 2$ \\
\hline 8689 & $5 \cdot 8$ & $5 \cdot 8$ & $\mathbf{0}$ \\
\hline 8690 & $5 \cdot 4$ & $5 \cdot 8$ & $0 \cdot 4$ \\
\hline 8691 & $5 \cdot 4$ & $5 \cdot 8$ & $0 \cdot 4$ \\
\hline 8692 & $5 \cdot 6$ & $6 \cdot 2$ & $0 \cdot 6$ \\
\hline 8693 & $5 \cdot 6$ & $6 \cdot 2$ & $0 \cdot 6$ \\
\hline 8694 & $5 \cdot 6$ & $5 \cdot 6$ & $\mathbf{0}$ \\
\hline 8695 & $5 \cdot 8$ & $6 \cdot 2$ & 0.4 \\
\hline 8696 & $5 \cdot 2$ & $5 \cdot 4$ & 0.2 \\
\hline 8835 & $5 \cdot 2$ & $5 \cdot 8$ & $0 \cdot 6$ \\
\hline 8844 & $5 \cdot 2$ & $5 \cdot 4$ & $0 \cdot 2$ \\
\hline 8845 & $5 \cdot 4$ & $5 \cdot 4$ & 0 \\
\hline 8847 & $5 \cdot 4$ & $5 \cdot 6$ & 0.2 \\
\hline $\mathbf{8 8 4 8}$ & $6 \cdot 0$ & $5 \cdot 8$ & $0 \cdot 2$ \\
\hline 8851 & $5 \cdot 4$ & $5 \cdot 4$ & 0 \\
\hline 8866 & $5 \cdot 6$ & $5 \cdot 8$ & $0 \cdot 2$ \\
\hline 418 (control) & $5 \cdot 8$ & $6 \cdot 0$ & 0.2 \\
\hline 8179 (control) & $5 \cdot 2$ & $5 \cdot 4$ & 0.2 \\
\hline
\end{tabular}

Mr-positive. Experiments with selected colonies suggested that the strains were pure cultures, but this point could only have been proved by single cell isolations. Wilson, Twigg, Wright, Hendry, Cowell \& Maier (1935), who used plating methods and single cell isolations, found that only one of thirty strains giving $\mathrm{MR}+, \mathrm{VP}+$ reactions was a mixed culture.

Most of the eighteen strains used here were MR-positive after $\mathbf{2 4} \mathrm{hr}$. at $\mathbf{3 0}{ }^{\circ}$, but by the third day, due to the acetoin production, reversal of reaction was occurring. Some strains did not revert within 5 days in certain batches of medium and experiments to discover the reason pointed to the peptone. One strain (NCTC 8696, Richards's R7) remained persistently mR-positive, a result which agreed with Richards's own findings (personal communication).

Of the three brands of peptone used one gave more Mr-positive results than the other two, but known differences between successive batches of the same peptone prevent the recommendation or condemnation of any particular brand.

In a medium without peptone, such as FR glucose salt broth, the strains which were initially MR-positive showed an earlier reversal of reaction, and all except NCTC 8696 had become negative by the second day. These experiments suggest that a glucose salt medium is better for the Mr test than one containing peptone, and that for coliforms the latter type of medium should be condemned. 


\section{REFERENCES}

Barritt, M. M. (1936). The intensification of the Voges-Proskauer reaction by the addition of $\alpha$-naphthol. J. Path. Bact. 42, 441.

BatTy-Smith, C. G. (1941). The detection of acetylmethylcarbinol in bacterial cultures. A comparative study of the methods of O'Meara and of Barritt. J. Hyg., Camb. 41, 521.

Chen, C. C. \& Rettger, L. F. (1920). A correlation study of the colon-aerogenes group of bacteria, with special references to the organisms occurring in the soil. J. Bact. 5, 253.

Clark, W. M. \& Lubs, H. A. (1915). The differentiation of bacteria of the colonaerogenes family by the use of indicators. J. infect. Dis. 17, 160.

Clark, W. M. \& LuBs, H. A. (1917). Improved chemical methods for differentiating bacteria of the coli-aerogenes family. J. biol. Chem. 30, 209.

Fouad, M. T. A. \& Richards, T. (1952). The use of glucose inorganic salts media in the classification of the coli-aerogenes bacteria. I. The methyl red and VogesProskauer reactions. Proc. Soc. appl. Bact. 16, 35.

Levine, M. (1916). The correlation of the Voges-Proskauer and methyl red reactions in the colon-aerogenes group of bacteria. J. infect. Dis. 18, 358.

Taylor, C. B., Clegg, L. F. L., Dowson, W. J., Hiscox, E. R. \& Richards, T. (1949). The classification of the coli-aerogenes bacteria. Report of the Coliform Sub-committee. Proc. Soc. appl. Bact. 12, 3.

Wilson, G. S., Twigg, R. S., Wright, R. C., Hendry, C. B., Cowell, M. \& Maier, I. (1935). The bacteriological grading of milk. Spec. Rep. Ser. med. Res. Coun., Lond. no. 206. 